\title{
DOCÊNCIA MASCULINA EM NAVIRAÍ/MS: VIVÊNCIAS E REPRESENTAÇÕES SOCIAIS
}

\author{
MALE TEACHING IN NAVIRAÍ/MS: EXPERIENCES \\ AND SOCIAL REPRESENTATIONS
}

\begin{abstract}
ENSEÑANZA MASCULINA EN NAVIRAÍ/MS: EXPERIENCIAS Y REPRESENTACIONES SOCIALES
\end{abstract}

\author{
Leonardo Alves de Oliveira ${ }^{\mathrm{I}}$ \\ Josiane Peres Gonçalves II

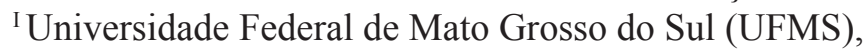 \\ Mato Grosso do Sul/MS - Brasil.

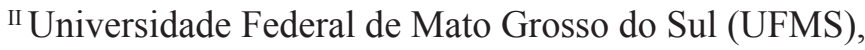 \\ Mato Grosso do Sul/MS - Brasil.
}

\begin{abstract}
RESUmo Ainda que a população brasileira seja majoritariamente formada por mulheres, é muito expressiva a parcela que elas constituem na composição do corpo docente da educação básica, especialmente na educação infantil e nos anos iniciais do ensino fundamental. Entre os fatores de ordem cultural, social, política e econômica que provocaram o processo de feminização do magistério, é importante destacar as representações, imagens e símbolos atribuídos aos profissionais docentes devido às possibilidades de serem ativados(as) pela atuação desses profissionais. Nesse sentido, considerando a pequena parcela de professores homens, a pesquisa desenvolvida pelo Grupo de Estudos e Pesquisa em Gênero, Desenvolvimento e Educação da UFMS buscou identificar as representações sociais relacionadas à atuação profissional de professores homens de educação infantil e anos iniciais do ensino fundamental por meio de entrevistas semiestruturadas gravadas, transcritas e analisadas. A utilização de grupos taxionômicos no estudo em representações sociais justificou-se pelo fato de os entrevistados (familiares, professores e gestores) comporem subgrupos que eventualmente possam se encontrar e pelos seus supostos interesses comuns no que diz respeito à educação de crianças. Os resultados revelam representações de gênero que se transpõem a homens e mulheres como professores em relações de contradição.
\end{abstract}

Palavras-chave: FormaÇão docente; Homens Professores; RepresentaÇões sociais. 
AbSTRACT Although the brazilian population is formed mostly by women, it is very expressive the portion that female teachers constitute in the school composition, especially in childhood education and early years of elementary school. Among cultural, social, political, and economic factors that caused the feminization of teaching, it is important to detach representations, images and symbols assigned to the teaching professionals due to the possibilities of being activated by the performance of these professionals. In this sense, considering the small portion of male teachers, this research developed by the UFMS Gender, Development, and Education Studies and Research Group, sought to identify social representations related to male professional performance in childhood education and early years of elementary school by recorded, transcribed and analyzed semi structured interviews. The using of taxonomic groups on this study in social representations is justifiable because the people interviewed (family, teachers and school managers) constitute subgroups that eventually they can meet each other or because of their supposed common interests about children education. The results indicate gender representations that are transposed to men and women as teachers in contradiction relations.

Keywords: TeACHER TRAINING; MALE TEACHERS; Social REPRESENTATIONS.

RESUMEN Aunque la población brasileña está compuesta principalmente por mujeres, la proporción que constituyen en la composición de la facultad de educación básica es muy significativa, especialmente en la educación de la primera infancia y en los primeros años de la escuela primaria. Entre los factores culturales, sociales, políticos y económicos que causaron el proceso de feminización de la enseñanza, es importante resaltar las representaciones, imágenes y símbolos atribuidos a los profesionales de la enseñanza debido a las posibilidades de ser activados por el desempeño de estos profesionales. En este sentido, considerando la pequeña cantidad de maestros varones, la investigación desarrollada por el Grupo de Estudios e Investigación en Género, Desarrollo y Educación de la UFMS, buscó identificar las representaciones sociales relacionadas con el desempeño profesional de los maestros varones de educación infantil y los primeros años de la escuela primaria. a través de entrevistas semiestructuradas grabadas, transcritas y analizadas. El uso de grupos taxonómicos en el estudio en representaciones sociales se justificó por el hecho de que los entrevistados (miembros de la familia, maestros y gerentes) componen subgrupos que eventualmente podrían conocer y por sus supuestos intereses comunes con respecto a la educación de los niños. Los resultados revelan representaciones de género que se transponen a hombres y mujeres como docentes en relaciones contradictorias.

Palabras Clave: Formación del profesorado; Maestros varones; Representaciones SOCIALES.

\section{INTRODUÇÃO}

A pesquisa ora apresentada resulta de uma investigação realizada com a comunidade escolar de Naviraí sobre o trabalho desenvolvido por docentes do gênero masculino com 
crianças de educação infantil e anos iniciais do ensino fundamental. Foram entrevistados, em cada uma das duas primeiras etapas da educação básica: professores homens, gestores escolares e familiares (pais ou responsáveis) de crianças matriculadas na rede municipal de ensino de Naviraí.

Os dados foram analisados de forma a considerar as diversas opiniões dos sujeitos pesquisados por meio de gravação de entrevistas semiestruturadas. Os resultados que retratam as representações sociais predominantes entre os participantes da pesquisa são apresentados na seção Encaminhamento Metodológico. Antes, porém, são exibidas algumas reflexões a respeito das representações sociais e presença masculina no magistério no Brasil.

De acordo com Jodelet (2001), o conceito, ainda em expansão, de representações sociais foi introduzido pelo psicólogo social romeno Serge Moscovici quando este publicou, em 1961, a versão em língua estrangeira de "A psicanálise, sua imagem e seu público". Segundo o autor, a representação social é:

[...] uma modalidade particular de conhecimento, cuja função é a elaboração de comportamentos e a comunicação entre os indivíduos. É um corpo organizado de conhecimentos e uma das atividades psíquicas graças às quais os homens fazem inteligíveis a realidade física e social, integram-se em um grupo ou em uma relação cotidiana de trocas, liberam os poderes de sua imaginação. [...] são sistemas de valores, noções e práticas que proporcionam aos indivíduos os meios para orientar-se no contexto social e material para dominá-lo. É uma organização de imagens e da linguagem. Toda representação social é composta de figuras e expressões socializadas. É uma organização de imagens e da linguagem porque recorta e simboliza atos e situações que são ou se transformam em comuns. Implica num enquadramento das estruturas, uma remodelagem dos elementos, uma verdadeira reconstrução do dado nos contextos de valores, noções e regras que logo depois, solidarizam-se. Uma representação social, fala, mostra, comunica, produz determinados comportamentos (MOSCOVICI, 2012, p. 43).

Dados do Censo Demográfico realizado pelo Instituto Brasileiro de Geografia e Estatística (IBGE, 2010) constataram que no ano de 2010 as mulheres compunham 51\% da população brasileira. Ainda que a população brasileira seja majoritariamente formada por mulheres, é muito expressiva a parcela que elas constituem na composição do corpo docente da educação básica nacional, especialmente na educação infantil e nos anos iniciais do ensino fundamental. De acordo com Gatti e Barreto (2009), ancorados na Pesquisa Nacional por Amostra de Domicílios (Pnad 2006), este levantamento demonstra que as professoras mulheres representam $67 \%$ dos profissionais docentes no ensino médio; $88,3 \%$ no ensino fundamental; e surpreendentes $98 \%$ na educação infantil. Por que os homens não atuam como professores nas mesmas proporções que as professoras mulheres ou por que existe essa diferença tão gritante entre a composição sexual dos docentes na educação básica nacional são certamente perguntas muito importantes, porém, nosso propósito com este trabalho não é responder a essas questões, mas sim identificar as representações sociais associadas à atuação de professores homens de educação infantil e anos iniciais do ensino fundamental, aproveitando o cenário e os atores que compõem esses níveis de ensino. 
Sendo as representações sociais formas de conhecimento, que servem como instrumentos para responder aos problemas do cotidiano (MOSCOVICI, 2012) socialmente elaboradas e compartilhadas, constituídas a partir das nossas experiências e das informações e modelos de pensamento que recebemos e transmitimos através da tradição, educação e comunicação (JODELET, 2001), concluímos que há utilidade em investigar suas associações à atuação do professor homem na educação infantil e nos anos iniciais do ensino fundamental para compreender o que se pensa sobre esses profissionais, pois se essas representações possuem caráter prático e interferem na atitude das pessoas, nada impede que componham, por exemplo, um dos fatores pelos quais há poucos homens trabalhando como professores nessas etapas de ensino.

\section{ENCAMINHAMENTO METODOLÓGICO}

O objetivo de investigar as representações sociais referentes à atuação de professores homens na educação infantil e nos anos iniciais do ensino fundamental originou-se no Grupo de Estudos e Pesquisa em Desenvolvimento, Gênero e Educação baseado na Universidade Federal de Mato Grosso do Sul (UFMS/CPNV). Para alcançar tal objetivo, criamos três roteiros para a realização de entrevistas semiestruturadas. O conteúdo das questões foi bastante semelhante, as poucas adaptações ocorreram devido ao fato de entrevistarmos três grupos taxionômicos diferentes, compostos por: familiares (entende-se pais e/ou responsáveis) de crianças matriculadas na educação infantil e no ensino fundamental; gestores de escolas ou instituições de educação infantil em que havia professores homens; e professores homens de educação infantil e ensino fundamental.

De acordo com Jodelet (2001), a representação de algo pressupõe a relação do sujeito que representa, com o objeto, que por sua vez é representado, e essa "máxima", apesar de ter gerado uma série de interpretações que poderiam tornar as representações sociais aplicáveis a qualquer objeto, em nosso estudo facilita a compreensão do processo em que se deu a pesquisa. O objeto de representação inicialmente considerado foi a atuação de professores homens na educação infantil e nos anos iniciais do ensino fundamental e os sujeitos "habilitados" para expressá-las foram, em nosso estudo, os grupos taxionômicos já citados, compostos por homens e mulheres de diferentes graus de formação num mesmo grupo. Ao todo, 29 entrevistas foram gravadas, transcritas e analisadas numa cidade do interior do Mato Grosso do Sul, com população de aproximadamente cinquenta mil habitantes.

A utilização de grupos taxionômicos (reunião de sujeitos individuais sob uma mesma classificação), justifica-se nesse caso pelo fato de que vários atores do contexto escolar local foram entrevistados e, dessa forma, não analisamos ou consideramos como representativo apenas uma parcela da população educacional local. Na verdade, o que este trabalho propõe é exatamente o oposto, ou seja, destacar representações presentes em todos os grupos taxionômicos estudados. Além disso, pelo fato de ser uma cidade relativamente pequena, a possibilidade de interação entre os sujeitos da pesquisa é muito mais provável. Um critério utilizado na seleção de familiares para as entrevistas, por exemplo, foi a assiduidade em reuniões escolares ou no contexto escolar como um todo, o que aumentava a 
possibilidade de contato com outros pais, bem como, outros atores da comunidade escolar e de os interesses com relação à educação de crianças serem compartilhados.

Para a coleta de dados, inicialmente fizemos contato com os participantes da pesquisa, e combinado o dia e horário em que seria possível gravar as entrevistas individualizadas. Antes de cada entrevista, foi realizada a leitura do Termo de Consentimento Livre e Esclarecido (TCLE) para elucidar os objetivos da investigação, os cuidados éticos adotados, assim como esclarecer quaisquer dúvidas sobre o estudo. Depois das explicitações, se fosse de interesse dos sujeitos contatados, os TCLE foram assinados e se deu início à gravação das entrevistas.

Cabe salientar que a utilização do TCLE visa garantir a proteção e o respeito aos direitos dos sujeitos participantes da pesquisa, pois segundo pontua a Resolução n ${ }^{\circ}$. 466/2012 do Conselho Nacional de Saúde (CNS), "O respeito devida à dignidade humana exige que toda pesquisa se processe com consentimento livre e esclarecido dos participantes, indivíduos ou grupos que, por si e/ou por seus representantes legais, manifestem a sua anuência à participação na pesquisa" (BRASIL, 2012, p. 5).

Quanto aos participantes da pesquisa, ao todo foram entrevistados: oito familiares de crianças matriculadas na educação infantil (FEI), com idades entre 35 e 73 anos; sete familiares de crianças matriculadas no ensino fundamental (FEF) e alunos/as de professores homens, com idades entre 30 e 50 anos; quatro gestores de instituições de educação infantil (GEI), com tempo de trabalho em educação entre 10 e 15 anos; quatro gestores de escolas em que há homens professores no ensino fundamental (GEF) com tempo de trabalho em educação de 12 a 29 anos; dois professores de educação infantil (PEI), ambos com mais de três anos de trabalho em educação; quatro professores de ensino fundamental (PEF) com tempo de trabalho em educação entre 3 e 23 anos. Todos os sujeitos envolvidos na pesquisa eram atores da rede de educação pública de Naviraí.

Há uma ressalva: houve dificuldade em encontrar homens professores na educação infantil, na verdade, esses sujeitos não foram encontrados - o que torna os dados do Pnad 2006 compreensíveis. Por conseguinte, não foi possível entrevistar gestores de instituições de educação infantil em que havia professores homens, mesmo que estas recebam estagiários homens com relativa frequência. Entretanto, entrevistamos um professor que passou por essa etapa de ensino, mas que posteriormente se tornou professor no ensino fundamental e outro professor que igualmente passou pela mesma etapa de ensino, mas que passou a lecionar no ensino superior e atuou, inclusive, como professor supervisor de estágio em educação infantil. Vale ressaltar que o nível de formação dos sujeitos de pesquisa em momento algum impediu a expressão das representações.

Como as representações sociais circulam nos discursos, são carregadas pelas palavras, mensagens, condutas (JODELET, 2001), nos pareceu coerente utilizar entrevistas como instrumentos de nossa pesquisa qualitativa. Essas características facilitam a observação das representações sociais, entretanto, por estarem "espalhadas por aí", na cultura, instituições, práticas sociais, comunicações interpessoais e de massa e nos pensamentos individuais, por serem difusas, fugidias, multifacetadas, há diversos impedimentos para que elas sejam captadas pela pesquisa científica de um modo direto e completo (SÁ, 1998). Nesse sentido, apresentamos aqui as representações sociais que atravessaram todos os grupos taxionômi- 
cos entre os adotados, evidenciando a sua circulação além de validade e relevância atribuída pela comunidade escolar local.

\section{RESULTADOS E DISCUSSÕES}

Primeiro, há o estranhamento. Especialmente com relação à educação infantil entre outros fatores, pelo fato de raramente haver homens professores nessa etapa da educação - há um estranhamento em relação à atuação desses profissionais.

É uma coisa assim meio estranha, porque eu nunca vi, acho meio estranho. Desde que eu me entendo por gente, eu não vi. Eu penso que seria melhor continuar do jeito que está (FEI 3).

Eu não sei, nunca vi um homem se adaptar a cuidar de criança pequena, então é uma coisa assim, que não dá para dar a opinião, se a gente nunca viu, né (FEI 4).

A princípio a gente viu assim que as expressões dos pais [...] achei que foi de bastante curiosidade e, assim, espanto... mas percebi que não houve nenhum comentário negativo a respeito da presença deles, não (GEI 1).

Só que assim, só que muitas pessoas acham muito estranho, muitas das vezes, um homem lá na educação infantil (PEI 1).

Porque é de tradição. A mulher é quem dá aula [...] E se toda profissão que não é próprio da mulher existe preconceito, quando a mulher está exercendo, quando não é profissão do homem também existe preconceito. Então a família rejeita muito o homem dentro da sala de aula (PEF 1).

A necessidade de compreender algo que é incomum e transformá-lo em algo familiar favorece a elaboração das teorias do senso comum. De acordo com Sá (1995), o estranho atrai, intriga e perturba as pessoas e comunidades e, por conseguinte, provoca nelas o medo de perder as referências atuais, o senso da comunidade e a compreensão mútua. Dessa forma, é compreensível porque FEI 3 prefere que as coisas continuem tal como estão.

Um dos processos geradores das representações sociais descritos por Moscovici é a ancoragem. Segundo Moscovici (2011, p. 61), a ancoragem é "quase como ancorar um bote perdido em um dos boxes de nosso espaço social". Esse processo é capaz de transformar algo estranho no sistema particular de categorias do sujeito que representa e compará-lo com um paradigma de uma categoria que o mesmo considera adequada. O que observamos, a partir dos resultados de nosso estudo, é que nesse processo de tornar o não-familiar em familiar os sujeitos da pesquisa basearam-se na referência de atuação profissional que lhes era habitual, ou seja, a atuação profissional de professoras. As representações identificadas foram, antes de tudo, representações de gênero, de características de homens e mulheres. Essas representações transferiram-se na fala dos entrevistados à atuação profissional de professores e professoras. No processo de comparação e qualificação, apresentaram-se as contradições entre professores e professoras. 
Quatro representações sociais atravessaram os três grupos taxionômicos: o (professor) homem é descuidado, inapto e/ou inadequado na atuação docente com crianças, ao contrário das mulheres; o (professor) homem é respeitável ou mais respeitável; o (professor) homem é a figura paternal na escola; e o (professor) homem é um pedófilo em potencial e sua relação com os alunos é erotizada.

Acho que homem não leva jeito [Risos]). Porque eu vejo, assim, o homem se embaraça todo para cuidar das crianças, então eu acho que mulher tem mais jeito. O homem até dá banho na criança, mas eu já tenho de casa isso, que eles não levam jeito (FEI 2).

Eu vejo que tem muita aquela coisa maternal mesmo, de mãe. Você cuida bem da criança. Talvez é uma coisa que..., que o homem não tenha noção, porque o pai é diferente da mãe (GEI 2).

A minha preocupação era a família, mas para minha surpresa, a relação com a família foi muito melhor do que eu imaginava, principalmente com as mães. Acho que, no caso dos pais, que eram dois que eu tinha... Era meio complicado. Teve momentos até de a diretora apresentar a atendente como professora (PEI 2).

Os excertos citados de entrevistas demonstram uma representação recorrente entre os sujeitos de pesquisa relacionados à educação infantil local. O mesmo não ocorre no ensino fundamental, na verdade acontece o contrário como veremos mais adiante. Talvez, a representação do professor homem como descuidado ou inadequado seja o cúmulo da desvalorização profissional. É a completa desconsideração de toda a trajetória de formação docente pela qual homens e mulheres passam ao optarem por um curso de Magistério e/ou Pedagogia.

Enquanto os homens são representados como descuidados na lida com crianças e essa representação é transferida aos professores homens, o inverso ocorre com as mulheres. Na verdade, essa representação se apoia numa qualificação e comparação da atuação profissional de professores homens e mulheres.

Então eu acho que a mulher tem mais jeito, para dar banho e tudo (FEI 2).

As mulheres estão de parabéns, elas cuidam muito bem mesmo (FEI 4).

Acho que a mulher leva mais jeito, por ser mãe ou algo do tipo (FEI 5).

A mulher tem um pouco mais assim, digamos, de paciência, de como eu posso dizer assim... Porque a criança nesta idade tem que ter muita paciência para lidar, então eu acho que a mulher, por ser um ser mais, digamos assim, a mulher é mais meiga, tem mais paciência. Então eu acho que a mulher, no meu modo de pensar, eu acho que a mulher dá mais certo para este tipo de trabalho (FEI 6).

Os homens estagiários em educação infantil que passaram por aquela instituição fizeram observações em turmas de crianças de 0 a 3 anos, mas, assim, no maternal não envolvia troca, não envolvia alguns cuidados. E mesmo que tivessem os cuidados, é claro que eles iam deixar para a professora ou outra acadêmica que fosse mulher (GEI 4). 
Aí tinha atividades, a gente fazia... aí eu levava os bebês para fora, porque eu sempre pensei assim que berço é lugar de dormir e em muitas instituições infelizmente as crianças ficam muito no berço e pouco no chão. Aí eu levava os colchões para fora, a gente tinha o momento de tomar sol e eu levava os bebês e tal. E aí a cozinheira da instituição ficava muito curiosa "O que eu ia fazer com aquelas crianças?”, mas é que o sol batia atrás da sala, então tinha que levar os bebês para trás da sala [risos]. Então ficava meio estranho isso, mas a atendente [profissional que auxilia professores e professoras de educação infantil] estava comigo e tal. E quando ela faltava era bem preocupante porque todo mundo se mobilizava, às vezes uma sala ficava sem professor, ou ficava com dois para ter alguém comigo, sempre com a presença de uma mulher, o que era muito interessante (PEI 2).

Além de os familiares explicitamente demonstrarem que as mulheres são mais adequadas ao trabalho com crianças na educação infantil, a fala de GEI 4 também naturaliza o trabalho de mulheres nessa etapa de ensino. Especialmente nas atividades em que exigem um contato físico maior com as crianças como nas falas destacadas (entre outras analisadas no decorrer da pesquisa) há uma atribuição de funções às mulheres, que muitas vezes é associado à maternidade ou ao suposto instinto maternal.

Aragão e Kreutz (2012) sinalizaram por meio de pesquisa com seis professoras de educação infantil a coexistência de duas representações sobre a docência, uma pautada em conhecimento teórico e outra entendida como dom ou vocacional. Com relação aos nossos dados, o que percebemos por meio das representações sociais que atravessaram os discursos dos três grupos de sujeitos entrevistados é que há uma desvalorização do conhecimento teórico ou da formação docente. Mesmo que os entrevistados, especialmente os gestores, em diversos momentos demonstrem certa aprovação ou receptividade pelo trabalho de professores homens, isso não os impediu de expressar as suas representações sociais ou aquelas das quais estão conscientes no cenário educativo em que atuam. Os gestores, por meio do discurso, demonstraram que os homens poderiam e seriam capazes de atuar profissionalmente na educação infantil, mas com relação às mulheres, essa capacidade parecia natural. Os professores homens, embora valorizando a formação docente, relataram várias representações sociais que qualificavam a atuação profissional de mulheres como superior devido ao fato de estas "terem mais jeito". É o caso por exemplo do professor que viu a gestora da instituição em que trabalhava apresentar sua ajudante como a professora de sua turma devido às representações dos familiares.

Nas comparações utilizadas para qualificar a atuação docente, a maioria dos sujeitos levou em consideração apenas uma parcela da educação que para eles parece satisfatória: o cuidado. Não há parcelamentos na educação infantil, pois como sabemos, essa etapa de ensino se caracteriza justamente pela inseparabilidade entre cuidar e educar (BRASIL, 1996; CERISARA, 1999; KRAMER, 2007). Somente por um suposto "instinto maternal" as mulheres são mais adequadas à educação infantil? Se assim fosse, os estudos, a graduação necessária, enfim, toda a formação docente, seriam desnecessárias, perda de tempo, pois mulheres poderiam apenas executar suas "habilidades naturais" a serviço das crianças.

No ensino fundamental, observamos um cenário diferente. Houve quem deu preferência aos homens devido a uma representação social que, por consequência, foi atribuída aos 
professores homens: a representação de que os (professores) homens são (mais) respeitáveis e têm mais autoridade. Ao expressarem essa representação, muitas vezes os sujeitos da pesquisa, implícita ou explicitamente comparam a postura de homens e mulheres e, por conseguinte, a atuação profissional de professores e professoras.

Eu acho assim, que com o professor homem, acho que os alunos iam ficar mais..., iam aprender mais, não iam ficar mais bagunçando. Agora, com mulher sempre eles começam a bagunçar. O homem, eles já começam e obedecem mais ao homem. [...] Porque mulher assim, eles falam: "É mulher". Ainda mais os meninos, os moleques, os rapazes. Eu acho que os alunos respeitam mais homem, porque assim eles têm um medo (FEF 4).

Eu acho que os alunos respeitam mais, têm mais aquela cisma, por ser homem. Porque a mulher, sei lá, eles... A mulher é mais doce e as crianças, acho que elas não têm muito aquele respeito com as professoras (FEF 7).

Os professores homens são muito próximos das crianças, porque o professor ele impõe uma postura forte. Quando o homem fala, os alunos têm medo. É, talvez não seria só pela questão de ter medo, mas a questão do respeito. [...] a figura de um homem também ajuda muito (GEF 1).

O professor, por ser do sexo masculino, ele tem uma tendência de ser mais rígido, ser mais objetivo nas coisas, [...] ele é mais claro, é isso pronto e acabou! Já a mulher, ela é mais 'mãezona', ela é uma mulher que é uma pedagoga, uma profissional, mas ela tem mais esse lado afetivo (GEF 4).

[...] em qualquer ambiente que você vai, que você vê que tem a figura masculina, a questão do respeito existe. Até para quem vai visitar a escola, pais e tal, é outra (PEI 1).

Ela [gestora da instituição em que o entrevistado trabalhava como professor de educação infantil] falava "O que você faz com eles?" E aí uma vez ela até perguntou: "Você briga, você ameaça?" Eu falei: "Não, não faço nada disso". Ela falava: "Então eu acho que é porque você é homem. Você é homem, então eu acho que eles te respeitam (PEI 2).

Olha, na minha opinião, sobre a presença do homem na escola, o aluno tem mais respeito pelo professor do que pela professora. [...] a imagem de homem na sala, as crianças ou os alunos têm mais um pouco de respeito (PEF 4).

Devido às questões culturais, e até mesmo por estarmos imersos em representações de gênero, não é impossível que os professores realmente deixem as crianças com mais receio o que provocaria comportamentos mais satisfatórios para os adultos na escola. Isso não significa, entretanto, que os homens sejam mais dignos de respeito ou que as professoras não tenham tanta autoridade quanto os professores. De qualquer forma, o que importa aqui é mais uma vez a contradição e a utilização da atuação profissional mais familiar para teorizar ou falar sobre a atuação profissional menos familiar, pois isso fortalece e distancia as representações. 
É importante destacar como todos os sujeitos envolvidos na pesquisa aprovaram os professores homens por essa suposta característica autoritária ou respeitável. Rabelo (2013), em pesquisa realizada no Brasil e em Portugal, categoriza a concepção de que o homem é incapaz de lidar com crianças como uma das discriminações que homens professores sofrem em sua trajetória profissional no ensino fundamental, e dentro dessa concepção ela enquadra a representação de que o professor homem é autoritário. Em nossa realidade local, essa característica está bem distante de tornar-se razão para discriminação, ao contrário. Se na educação infantil os professores parecem inadequados, no ensino fundamental parecem necessários devido à indisciplina que caracteriza não só a comunidade escolar pesquisada, mas um desafio da educação brasileira atual. Por vezes, a representação do professor homem como autoridade se apoiou na representação do professor homem como figura paternal na escola.

Eu acredito... por ser raro a presença [de professores homens na educação infantil], eles gostam demais, eles queriam ficar perto, eles queriam abraçar, tendo em vista também que parte das nossas famílias não têm esta representatividade paterna dentro de casa. Penso eu então, que os alunos associam também, que eles têm esta carência (GEI 4).

É fundamental (a presença de professores homens) dentro de uma escola [...] tão importante quanto a das mulheres e não só pelo nível de conhecimento, mas por ter a figura masculina na escola [...] Grande parte dos alunos vê o professor homem também como pai (GEF 1).

O homem tem que participar também da educação do aluno. Também em casa já acontece, o pai ajuda e na escola o professor está como pai do aluno. Então eu acho importante que tenha professores homens (FEF 7).

Muitas crianças não têm a figura masculina em casa, então o professor passa a ser essa figura masculina que eles buscam (GEF 3).

Tanto lá na educação infantil quanto no primeiro, segundo, terceiro, quarto ano, a gente sendo homem, você vê que tem coisas que a maioria das crianças não tem em casa, que é o carinho do pai. E quando eles têm um professor homem, até em questão de disciplina, você controla com mais facilidade [...] talvez por falta dessa afetividade, você ganha campo, você sendo homem, você ganha campo (PEI 1).

As crianças buscam um pai em você, porque talvez ela não tem um pai. Aquele carinho que ela não tem em casa do pai, você tem que atender essa criança, procurando esse carinho para ela (PEF 3).

Alguns autores apontam aspectos positivos no trabalho de homens como professores de crianças (ERDEN et al., 2011; RAMOS, 2011, MOSSBURG, 2004). Um desses aspectos é suprir a ausência do pai quando as crianças são criadas apenas pela mãe, porém não há comprovação empírica para tal afirmação (MONTEIRO; ALTMANN, 2013). 
Interpretamos que assim como a professora é representada como "mãezona", o professor é representado como pai. E nessa altura das discussões, suspeitamos que isso se deva a representações do que seja a função das escolas, das instituições de educação infantil e dos próprios educadores.

Com as mudanças resultantes do trabalho, na atualidade pais e mães passam menos tempo com seus filhos e dessa forma adultos e crianças têm obrigações e ocupações durante o dia. Nesse sentido, ocorre uma atribuição de obrigações à escola e, por conseguinte, aos seus profissionais, obrigações com as quais, muitas vezes, nem os pais podem lidar. Santos (2007), em pesquisa que aborda relações entre família e escola no processo de socialização primária, entrevistou pais que reconheciam ser impossível ou muito difícil se responsabilizar pelo desenvolvimento de normas e padrões de etiqueta, conduta, comportamento e interação social e que atribuem à escola a maior responsabilidade pela inserção no universo de normas de civilidade.

O que constatamos é que na educação infantil ou no ensino fundamental, as atribuições e representações associadas aos professores e professoras estão ligadas à delegação de tarefas aos profissionais da educação e às instituições de educação, de forma a compensar a impossibilidade ou dificuldade de os próprios familiares executá-las: a "mãezona" "tem jeito" para cuidar de criança, logo, é adequada para ser professora na educação infantil, já o homem é "descuidado" o que o torna inadequado, portanto a função da educação infantil é cuidar de crianças; o homem é (mais) respeitável, tem mais autoridade, portanto disciplinará as crianças enquanto os pais trabalham; os professores homens são a figura paternal na escola, além de suas tarefas como professores eles desempenharão papéis de pais? E, finalmente, a mais séria, velada e presente representação social: a representação de que o professor é um pedófilo em potencial e/ou tem uma relação erotizada com seus alunos, especialmente alunas.

[...] em certas situações, não sei, como trocar as crianças. Sei lá... Tipo assim... Uma troca de fralda, ou uma situação mais íntima, principalmente com a menina, eu acho que seria um pouco constrangedor para o professor homem, não sei se eu estou certa (FEI 1).

Eu acho que o mais certo é você acompanhar o seu filho e sempre conversar muito, porque tem aquele perigo: é uma menina, é uma moça, entendeu? Mas eu acho que se a gente conversar, se a gente participar, sempre que possível, porque às vezes tem mãe que trabalha e não tem condições de ir acompanhar os filhos no ambiente escolar (FEF 6).

Os homens que fizeram estágio na educação infantil não trocaram as crianças e a gente não ia deixar mesmo. Mas eu acho que é um receio da pessoa, porque a gente vive em um mundo tão turbulento, é claro que isto não cabe a nenhum dos estagiários que passou por aqui, mas a própria sociedade já olha com um olhar diferente para os professores homens (GEI 4).

Eu até trabalhei com uma menina cadeirante, que quando ela fazia suas necessidades, num determinado tempo, eu tinha alguém que me auxiliava. É que eu tinha amizade com a pessoa que trabalhava nos serviços gerais e falei “Óh, você 
vai ter que me ajudar, porque não tem como ir ao banheiro e trocar a menina, eu sou homem e é muito difícil". É que se um pai vai e vê algo que pode não gostar e então é uma situação difícil (PEI 1).

Na hora do banho eu preferia, para não ter comentários, trocar... Então a professora da outra sala deixava os meninos dela comigo e eu ficava com os meus e eu passava as minhas meninas para ela. Então ela dava banho em todas as meninas e eu em todos os meninos. Eu acho importante também a gente participar dessas atividades, embora tinha a recreadora para ajudar, mas é importante não dividir as crianças (PEI 2).

De acordo com Ramos (2011), o cuidado físico, quando executado por educadores/ cuidadores homens representa, para pais, uma ameaça à integridade física da criança, o que pode limitar as atividades por eles realizadas. Essa ameaça, no entanto, não é sentida quando as mesmas atividades são feitas por professoras mulheres, pois elas "trazem consigo a vocação para a maternidade e elas são, por natureza, quem protege e cuida dos filhos com desvelo e são incapazes de cometer maldade contra as crianças" (RAMOS, 2011, p. 107). Dessa forma, temendo a sexualidade masculina, é como se faltasse sexualidade à mulher, como se ela não possuísse impulsos sexuais causadores de corrupção (RABELO, 2013).

O medo da pedofilia torna a educação infantil um espaço não tão receptivo ao professor homem, pois é a etapa da educação em que há maior contato físico entre professor e aluno/criança. Considerando que essa é a representação social de maior expressão, mesmo implicitamente, com certeza se configuraria como mais um fator que tornaria o professor homem inadequado para a educação infantil.

A educação infantil sempre foi composta majoritariamente por professoras mulheres, mas isso não ocorreu com o ensino fundamental, por exemplo, que já foi composto essencialmente por homens. Consideramos os fatores de ordem econômica e política, e social, as transformações no trabalho como causadores de uma (des)masculinização do magistério, processo esse permeado no âmbito dos fatores sociais por imagens, significações e representações atribuídos a professores e professoras, algo sustentado por diversos estudos (LOURO, 1997; CARVALHO, 1998; GONÇALVES, 2009, MATTOS, 2011; MONTEIRO, ALTMANN, 2013; RABELO, 2013). Como as representações podem contribuir para essa organização, acreditamos que a reprodução de que o homem professor é um pedófilo em potencial contribui para afastar homens da profissão docente nessa etapa da educação, assim como torná-los indesejáveis.

Generalizar atitudes de professores e professoras é imprudente, especialmente no que diz respeito à pedofilia, pois concordando com Moreira e Santos (2002), há diferentes perfis de feminilidade e masculinidade compondo o cenário da docência escolar, portanto os homens não se comportam sempre da mesma forma, o mesmo ocorre com as mulheres, $\mathrm{e}$ isso considerando-se apenas a complexidade dos gêneros, ou seja, sem conceituar as diversas formações pelas quais cada professor passa e, por conseguinte, pelas competências e habilidades desenvolvidas em formação e no exercício da profissão. 
Quadro 1 - Abrangência de Representações Sociais por Grupo Taxionômico.

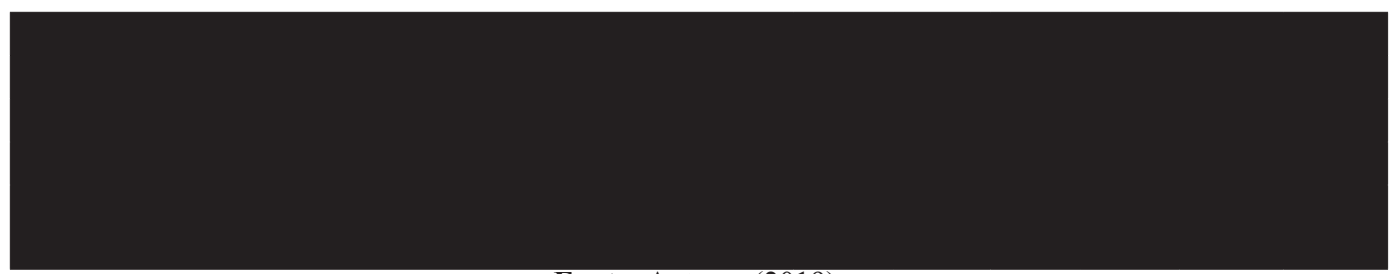

Fonte: Autores (2019).

\section{CONSIDERAÇões FINAIS}

No que diz respeito à atuação de professores e professoras com crianças, o gênero mostra-se como uma categoria de análise essencial, tendo em vista que a profissão docente é representada de acordo com o gênero antes da própria formação profissional. Utilizando a atuação profissional de professoras como ponto de partida, foram estabelecidas comparações que em relações de contradição caracterizaram homens e mulheres e, por conseguinte, suas próprias atuações profissionais, num processo propenso a fortalecer e distanciar representações sociais.

A maioria das representações identificadas evidencia que as funções dos familiares de crianças são confundidas com as funções de professores e professoras, e a partir da ideia de qual profissional pode cumprir melhor tais funções é que são definidas as preferências e as concepções de profissional (mais) adequado para cada etapa de ensino.

Alguns sujeitos da pesquisa possuíam um discurso favorável à presença de homens em cada etapa de ensino, mas isso não os livrava da convivência em um cenário educativo em que há representações que nem sempre tornam essa presença tão favorável. Nesse sentido, mesmo não concordando com determinadas representações sociais, isso não os impediu de expressá-las.

Considerando que as representações sociais interferem na atitude de pessoas e grupos, estimulamos estudos que busquem compreender e divulgar representações sociais da profissão docente, mas especialmente das funções da escola, da família e dos professores, como forma de contribuir para a desconstrução de preconceitos, mesmo que o alcance seja inicialmente no meio acadêmico.

\section{REFERÊNCIAS}

ARAGÃO, M. KREUTZ, L. Educação infantil e formação de professores: narrativas docentes em pauta. In: IX ANPEDSUL: Seminário de Pesquisa em Educação da Região Sul. Caxias do Sul, 2012. Disponível em: $<$ http://www.ucs.br/etc/conferencias/index.php/ anpedsul/9anpedsul/paper/viewFile/437/552> Acesso em: 4 ago. 2019.

BRASIL. Congresso Nacional. Lei de Diretrizes e Bases da Educação Nacional. Lei n. 9.394/96. Diário Oficial da União, Brasília, DF, 23 de dez. 1996. 
BRASIL. Resolução $\mathrm{n}^{0}$. 466, de 12 de dezembro de 2012. Trata de pesquisas e testes em seres humanos. Disponível em: https://conselho.saude.gov.br/resolucoes/2012/Reso466. pdf. Acesso em: 12 jun. 2019.

CARVALHO, M. P. Vozes Masculinas numa profissão feminina. Estudos Feministas, Santa Catarina, v. 6, n. 2, p. 406-422, jun./dez. 1998.

CERISARA, A. B. Professoras de educação infantil: entre o feminino e o profissional, 2. ed. São Paulo: Cortez, 2002.

ERDEN, S.; OZGUN, O.; CIFTCI, M. A. "I am a man, but I am a pre-school teacher": Self- and social-perception of male pre-school teachers. Procedia Social and Behavioral Sciences, v. 15, 2011, p. 3199-3294. Disponível em: <http://ac.els-cdn.com/S1877042811008172/1-s2.0-S1877042811008172-main.pdf?_tid=82ad5c82-fd58-11 e4-ab05-00000aacb361\&acdnat=1431951912_61822247eea6733e0acf4d54ab59b228>. Acesso em: 10 mai. 2019.

GATTI, B.; BARRETO, E. S. Professores do Brasil: impasses e desafios. Brasília: UNESCO, 2009.

GONÇALVES, J. P. O perfil profissional e representações de bem-estar docente e gênero em homens que tiveram carreiras bem-sucedidas no magistério, 232s. Tese (Doutorado em Educação) - Pontifícia Universidade Católica do Rio Grande do Sul, PUC/RS, Porto Alegre, 2009.

IBGE. Resultados Gerais da Amostra do Censo Demográfico 2010. Disponível em: http://biblioteca.ibge.gov.br/visualizacao/periodicos/99/cd_2010_resultados_gerais amostra.pdf. Acesso em: 1 ${ }^{\circ}$. abr. 2019.

JODELET, D. Representações sociais: um domínio em expansão. In: Jodelet, D. (Org.). As representações sociais. Rio de Janeiro: EdUERJ, p. 17-44, 2001.

KRAMER, S. Profissionais de educação infantil: gestão e formação. São Paulo: Ática, 2007.

LOURO, G. L. Gênero, sexualidade e educação. Uma perspectiva pós-estruturalista. Petrópolis: Vozes, 1997.

MATTOS, H. M. Z. H. A questão do gênero e a formação da professora da educação infantil, 201s. Dissertação (Mestrado em Educação) - Pontifícia Universidade Católica do Paraná, PUC/PR, Curitiba, 2011.

MONTEIRO, M. K.; ALTMANN, H. Trajetórias na docência: professores homens na educação infantil. In: $36^{\mathrm{a}}$ Reunião Anual da ANPEd, 2013, Goiânia/GO. Anais da 36a Reunião Anual da Anped. Goiânia: Anped, 2013, v. 1, p. 1-17.

MOREIRA, M. F. S., SANTOS, L. P. Indisciplina na escola: uma questão de gênero? In: Educação em Revista, n. 3, p. 141-160, 2002. 
MOSCOVICI, S. A psicanálise, sua imagem e seu público. Petrópolis: Vozes, 2012.

MOSCOVICI, S. Representações sociais: investigações em psicologia social, 8. ed. Petrópolis, RJ: Vozes, 2011.

MOSSBURG, Marc W. Male early childhood teachers: shaping their professional identity. Pro-quest dissertations and theses, 2004. Dissertação de doutorado. Arizona State University (EUA).

RABELO, A. O. Professores discriminados: um estudo sobre os docentes do sexo masculino nas séries do ensino fundamental. Educação e Pesquisa, São Paulo, v. 39, n. 4, dez. 2013.

RAMOS, J. Um estudo sobre os professores homens da educação infantil e as relações de gênero na Rede Municipal de Belo Horizonte - MG, 2011, 139s. Tese (Doutorado em Educação) - Pontifícia Universidade Católica de Minas Gerais, PUC/MG. Disponível em: <http://www.biblioteca.pucminas.br/teses/Educacao_RamosJ_1.pdf $>$. Acesso em: 10 mai. 2019.

SÁ, C. P. A construção do objeto de pesquisa em representações sociais. Rio de Janeiro: EdUERJ, 1998.

SÁ, C. P. Representações Sociais: o conceito e o estado atual da teoria. In: SPINK, M. J. (Org.). O conhecimento no cotidiano. São Paulo: Brasiliense, 1995.

SANTOS, R. O papel da família e da escola no processo contemporâneo de socialização primária. In: X Simpósio Internacional Processo Civilizador, 2007, Campinas. Sociabilidades e Emoções: anais do X Simpósio Internacional Processo Civilizador. Campinas: Unicamp, 2007.

\section{DADOS DOS AUTORES:}

\section{Leonardo Alves de Oliveira}

Graduado em Pedagogia pela Universidade Federal de Mato Grosso do Sul/MS-Brasil. Professor da Rede Municipal de Ensino de Naviraí. Mato Grosso do Sul/MS-Brasil. leo1. dioliveira@hotmail.com

\section{Josiane Peres Gonçalves}

Pós-Doutorado pela Pontifícia Universidade Católica do Rio Grande do Sul/RS-Brasil. Professora do Programa de Pós-graduação em Educação da Universidade Federal de Mato Grosso do Sul. Pantanal. Mato Grosso do Sul/MS-Brasil. josianeperes7@hotmail.com

Submetido em: 2-6-2020

Aceito em: 17-11-2020 